\title{
Are sleep disorders associated with increased mortality in asthma patients?
}

Kyu-Tae Han ${ }^{1,2+}$, Hong-Chul Bae ${ }^{1,3 \dagger}$, Sang Gyu Lee ${ }^{2,4}$, Seung Ju Kim², ${ }^{1,2}$ Woorim Kim ${ }^{1,2}$, Hyo Jung Lee ${ }^{1,2}$, Yeong Jun Ju', and Eun-Cheol Park ${ }^{1,2,5^{*}}$

\begin{abstract}
Background: South Korea has experienced problems regarding poor management of symptoms of asthma patients and remarkable increases in sleep disorders. However, few studies have investigated these issues. We examined the relationship between sleep disorders and mortality in asthma patients to suggest effective alternatives from a novel perspective.

Methods: We used data from the National Health Insurance Service (NHIS) National Sample Cohort 2004-2013, which included medical claims filed for 186,491 patients who were newly diagnosed with asthma during the study period. We performed survival analyses using a Cox proportional hazards model with time-dependent covariates to examine the relationship between sleep disorders and mortality in asthma patients.

Results: There were 5179 (2.78\%) patients who died during the study period. Sleep disorders in patients previously diagnosed with asthma were associated with a higher risk of mortality (hazard ratio [HR]: 1.451, 95\% confidence interval [CI]: 1.253-1.681). In addition, significant interaction was found between sleep disorders and Charlson comorbidity index.

Conclusions: Our findings suggest that an increased prevalence of sleep disorders in asthma patients increases the risk of mortality. Considering the worsening status of asthma management and the rapid growth of sleep disorders in South Korea, clinicians and health policymakers should work to develop interventions to address these issues.
\end{abstract}

Keywords: Sleep disorders, Asthma, Mortality, Healthcare accessibility, Vulnerable population

\section{Background}

Asthma is a common chronic disease largely caused by genetic and environmental risk factors such as indoor and outdoor allergens, smoking, chemical irritants in the workplace, and air pollution. Its symptoms include recurring periods of wheezing, chest tightness, shortness of breath, and coughing [1]. In severe cases, asthma can lead to death. According to a World Health Organization (WHO) report, about 235 million people suffer from asthma worldwide, and it is especially severe for children in low- and middle-income countries [2]. Although asthma

\footnotetext{
* Correspondence: ecpark@yuhs.ac

${ }^{\dagger}$ Equal contributors

'Department of Public Health, Graduate School, Yonsei University, Seoul, Republic of Korea

${ }^{2}$ Institute of Health Services Research, Yonsei University College of Medicine,

Seoul, Republic of Korea

Full list of author information is available at the end of the article
}

is not curable, optimal management can control symptoms and improve the quality of life of patients.

To determine the optimal management of asthma patients, numerous previous studies have been conducted, revealing many risk factors related to worsening status of asthma patients including clinical, socioeconomic, seasonal, and environmental factors [3-10]. Nevertheless, concerns remain regarding the management of worsening asthma in South Korea. According to the Organization for Economic Co-operation and Development (OECD) Health at a Glance 2015, asthma management in South Korea is worse than in other OECD countries; specifically, hospital admission rates for asthma patients are 98.5 per 100,000 people in South Korea compared to the average of 43.8 per 100,000 people in other OECD countries [11]. To solve the problems related to inappropriate management, the Health Insurance Review \& Assessment service (HIRA) introduced 
a quality evaluation for asthma in 2013. However, it is also essential to assess problems related the poor level of asthma management from alternative perspectives. Here, we focus on the link between outcomes of asthma patients and sleep disorders. Sleep is intimately related to many aspects of an individual's life, and sleep disorders may contribute to both physical and mental problems. According to previous studies, sleep disorders and problems such as low quality of sleep or short sleeping time could result in deteriorating conditions in patients with chronic diseases, including asthma, and in severe cases, sleep disorders were even associated with mortality in patients [12-14].

In South Korea, sleep issues have become increasingly common. According to National Health Insurance Service (NHIS) reports, health resource utilization due to organic sleep disorders (International Classification of Diseases [ICD]-10: G47) has gradually increased in South Korea, with the number of inpatients and outpatients growing from 358,062 in 2012 to 380,876 in 2013 and 414,524 in 2014 [15]. Now, it has become a major concern that needs to be solved and has even gained the media spotlight recently. Despite these remarkable increases over the last several years, few studies have investigated the negative impact of sleep disorders in South Korea. In this study, we analyzed the association between sleep disorders and mortality as the outcome variable among patients who were diagnosed with asthma, thereby considering the poor quality of asthma patient management and considerable increases in sleep disorders in South Korea. Based on this study, we expected to be able to develop alternatives for the optimal management of asthma in South Korea.

\section{Methods}

\section{Study population}

The data used in this study were obtained from the NHIS National Sample Cohort 2002-2013 that was released in 2014. They comprised a nationally representative random sample of 1,025,340 individuals, approximately $2.2 \%$ of the entire NHIS population in 2002 . The data were produced by the NHIS using a systematic sampling method to generate a representative sample of 46,605,433 Korean residents recorded in 2002 . The database included all medical claims filed from January 2002 to December 2013. To investigate the association between sleep disorders and mortality in patients with diagnosed asthma, we included only patients who were newly diagnosed with asthma (ICD-10: J45) during outpatient care after 2004. We then excluded patients diagnosed with a sleep disorder (ICD-10: G47) prior to the diagnosis of asthma to limit our investigation to the effect of sleep disorders on patients who had already experienced asthma. Ultimately, the data used in this study were from 186,491 patients newly diagnosed with asthma from 2004-2013. Regional characteristics were determined from the "e-provincial indicators" published by Statistics Korea, which contained the regional demographic structures for all 253 basic administrative si-gun-gu (city-county-ward) districts of South Korea. We classified the data based on the si-gun-gu information to take into account the regional characteristics of the community in which each patient resided (Statistics Korea) [16].

\section{Variables}

The outcome variable was mortality in patients diagnosed with asthma (ICD-10: J45). Mortality was defined as all types of death in patients with asthma during the study period. We identified the date of each patient's first hospital visit through either outpatient care or admission during the study period, and we followed each patient after that date.

The primary independent variable in relation to the mortality of patients with asthma was whether they were diagnosed with an organic sleep disorder during follow-up (ICD-10: G47). We adjusted both patient and regional variables when analyzing the effect of sleep disorders on mortality in patients with asthma. The patient variables included in the analyses were sex, age, income, insurance coverage type, year of first asthma diagnosis, disability, Charlson comorbidity index score, and average annual pharmaceutical expenditures for asthma. Age was divided into 10-year groups $(\leq 19,20-29,30-39,40-49,50-59,60-$ 69 , and $\geq 70$ years) to reflect any differences in the effects of sleep disorders on mortality among patients with asthma by age group. Income level was categorized into deciles based on mean household income as follows: $\leq 10 \%, 11 \%$ 20\%, 21\%-30\%, 31\%-40\%, 41\%-50\%, 51\%-60\%, 61\%-70\%, $71 \%-80 \%, 81 \%-90 \%$, and $\geq 91 \%$. The types of insurance coverage were categorized as medical aid, National Health Insurance (NHI) employee insurance, or NHI self-employed insurance based on the NHI criteria. Those with NHI employee insurance included workers and employers in all workplaces, public officials, private school employees, continuously insured persons, and daily paid workers at construction sites. Beneficiaries of NHI employee insurance included spouses, descendants, siblings, and parents. People with NHI employee insurance paid a regular portion (about 7\%) of their average salary in contribution payments, and the rates changed every year. The NHI self-employed insurance category included people who did not fall into the above-described group. Their contribution amount was set by taking into account their income, property, living standard, and rate of participation in economic activities. Medical aid beneficiaries were defined as patients with an income below the governmentdefined poverty level or a disability who were provided with free inpatient and outpatient care paid with government funds. Therefore, the type of insurance coverage 
represented each patient's socioeconomic status [17, 18]. The first diagnosis for asthma was defined as the year that each patient was initially diagnosed and was included to reflect the duration of illness. Disability was classified as none, mild, and severe to reflect the effect of disability on worsening health outcomes in patients with asthma. The Charlson comorbidity index was calculated by weighting and scoring for comorbid conditions, with additional points added to consider comorbidities that could affect health outcomes of patients with asthma. Average annual pharmaceutical expenditures for asthma were calculated as the average of the sum of pharmaceutical expenditures every year after asthma diagnosis (ICD-10: J45). This could indirectly reflect the level of treatment and asthma severity.

The regional variables were region, number of medical centers per 1000 residents, population size, proportion of seniors, and financial independence rate of the local government. The region types were metropolitan and other. Population size was defined as the total number of residents in each community, and the proportion of seniors was the number of elderly individuals among the entire community. The financial independence rate of the local government was an index of the finance utilization capacity of a local government with independent discretionary power. This indicator was calculated as follows: (local taxes + non-tax revenue)/local government budgets $\times 100$.

\section{Statistical analysis}

We first examined the frequencies and percentages of each categorical variable at each patient's baseline and performed $\chi^{2}$ tests to examine the distribution for mortality according to each variable. We examined the mean and standard deviation of each continuous variable at baseline and performed $t$-tests or Wilcoxon-Mann-Whitney tests for each variable by mortality during the study period. Analyses were performed for both patient- and regionallevel variables. Kaplan-Meier survival curves and log-rank tests were used to compare survival rates between groups. We performed survival analyses using a Cox proportional hazards model with time-dependent covariates to examine factors associated with mortality [19]. Subgroup analyses by age group, insurance coverage type, average annual pharmaceutical expenditures for asthma, region, $\mathrm{CCI}$, and number of medical centers were used to investigate the relationship between sleep disorders and mortality in patients with asthma. All statistical analyses were performed using SAS statistical software version 9.2 (Cary, NC).

\section{Results}

The data used in the analysis were collected from 186,491 patients with asthma. Table 1 shows their general characteristics at baseline (at asthma diagnosis) and the descriptive statistics for mortality. There were 5179 patients (2.78\%) who died during the study period (major causes of death = lung cancer: $10.5 \%$, senility: $6.1 \%$, COPD: $4.5 \%$, myocardial infarction: $4.4 \%$, and stomach cancer: $3.7 \%$ among total deaths). The average follow-up period was 62.17 months. Patient with sleep disorders more frequently appeared in the died criteria than the survived criteria. Those who were medical aid beneficiaries also had a higher risk, as did patients with longer illness durations, severe disabilities, more comorbidities, and higher pharmaceutical expenditures. With regard to regional variables, patients in non-metropolitan regions had higher mortality.

Figure 1 shows Kaplan-Meier survival curves and log-rank test results of the study population. The average period from first diagnosis to death was shorter in patients with sleep disorders (mean: 103.85 months, standard error [SE]: 0.56) than in those without sleep disorders (mean: 116.05, SE: 0.04; $p<0.0001$ ).

Table 2 shows the results of the survival analysis using a Cox proportional hazard model with time-dependent covariates to investigate the relationship between sleep disorders and mortality in patients with asthma. Those with sleep disorders had a greater risk of mortality (with sleep disorder, hazard ratio [HR]: 1.451, 95\% confidence interval $[\mathrm{CI}]$ : 1.253-1.681; reference: without sleep disorder). Males and older patients were at greater risk, as were asthma patients with lower incomes and those who received medical aid (medical aid, HR: 1.546, 95\% CI: 1.317-1.814; NHI self-employed insurance, HR: 1.126, 95\% CI: 1.061-1.195; reference: NHI employee insurance). For regional variables, patients in metropolitan regions were at lower risk, and higher financial independence of the local government was inversely associated with mortality risk.

We performed interaction tests to further examine potential effect modification of the associations between sleep disorders and mortality by age, insurance coverage, pharmaceutical expenditures, region, number of medical centers per 1000 residents and the CCI. Except for CCI, the interaction terms between sleep disorders and the mentioned variables were not statistically significant. Nevertheless, a trend in the magnitude of the stratified HR was observed for age and insurance coverage. For age, the highest HR were observed among younger age groups. For insurance coverage, higher HR were observed for NHI self-employed insurance than for NHI employee insurance. In addition, the association between sleep disorders and mortality was stronger in non-metropolitan regions compared with metropolitan areas, and among individuals with lower number of medical centers per 1000 residents. For $\mathrm{CCI}$, the interaction term between sleep disorders and CCI was statistically significant. And, higher HR were observed among higher CCI group (Table 3 ). 
Table 1 General characteristics of the study population

\begin{tabular}{|c|c|c|c|c|c|c|c|}
\hline \multirow[t]{2}{*}{ Variable } & \multicolumn{2}{|l|}{ Total } & \multicolumn{2}{|l|}{ Died } & \multicolumn{2}{|l|}{ Survived } & \multirow[t]{2}{*}{$P$-value } \\
\hline & n/Mean & $\% / S D$ & n/Mean & $\% / S D$ & n/Mean & $\% / S D$ & \\
\hline \multicolumn{8}{|l|}{ Sleep disorder } \\
\hline Yes & 4,565 & 2.45 & 320 & 6.18 & 4,245 & 2.34 & \multirow[t]{2}{*}{$<0.0001$} \\
\hline No & 181,926 & 97.55 & 4,859 & 93.82 & 177,067 & 97.66 & \\
\hline \multicolumn{8}{|l|}{ Sex } \\
\hline Male & 83,801 & 44.94 & 2,819 & 54.43 & 80,982 & 44.66 & \multirow[t]{2}{*}{$<0.0001$} \\
\hline Female & 102,690 & 55.06 & 2,360 & 45.57 & 100,330 & 55.34 & \\
\hline \multicolumn{8}{|l|}{ Age (years) } \\
\hline$\leq 19$ & 80,859 & 43.36 & 62 & 1.20 & 80,797 & 44.56 & \multirow[t]{7}{*}{$<0.0001$} \\
\hline $20-29$ & 13,342 & 7.15 & 26 & 0.50 & 13,316 & 7.34 & \\
\hline $30-39$ & 21,861 & 11.72 & 89 & 1.72 & 21,772 & 12.01 & \\
\hline $40-49$ & 20,849 & 11.18 & 213 & 4.11 & 20,636 & 11.38 & \\
\hline $50-59$ & 18,911 & 10.14 & 449 & 8.67 & 18,462 & 10.18 & \\
\hline $60-69$ & 16,170 & 8.67 & 1,047 & 20.22 & 15,123 & 8.34 & \\
\hline$\geq 70$ & 14,499 & 7.77 & 3,293 & 63.58 & 11,206 & 6.18 & \\
\hline \multicolumn{8}{|l|}{ Income (percentile) } \\
\hline$\leq 10$ (low) & 14,779 & 7.92 & 816 & 15.76 & 13,963 & 7.70 & \multirow[t]{10}{*}{$<0.0001$} \\
\hline $11-20$ & 10,388 & 5.57 & 330 & 6.37 & 10,058 & 5.55 & \\
\hline $21-30$ & 11,584 & 6.21 & 370 & 7.14 & 11,214 & 6.18 & \\
\hline $31-40$ & 13,884 & 7.44 & 405 & 7.82 & 13,479 & 7.43 & \\
\hline $41-50$ & 16,266 & 8.72 & 370 & 7.14 & 15,896 & 8.77 & \\
\hline $51-60$ & 19,443 & 10.43 & 421 & 8.13 & 19,022 & 10.49 & \\
\hline $61-70$ & 22,858 & 12.26 & 440 & 8.50 & 22,418 & 12.36 & \\
\hline $71-80$ & 26,097 & 13.99 & 542 & 10.47 & 25,555 & 14.09 & \\
\hline $81-90$ & 26,628 & 14.28 & 716 & 13.83 & 25,912 & 14.29 & \\
\hline$\geq 91$ (high) & 24,564 & 13.17 & 769 & 14.85 & 23,795 & 13.12 & \\
\hline \multicolumn{8}{|l|}{ Insurance coverage } \\
\hline Medical aid & 3,934 & 2.11 & 269 & 5.19 & 3,665 & 2.02 & \multirow[t]{3}{*}{$<0.0001$} \\
\hline $\mathrm{NHI}$, self-employed insured & 63,816 & 34.22 & 2,044 & 39.47 & 61,772 & 34.07 & \\
\hline $\mathrm{NHI}$, employee insured & 118,741 & 63.67 & 2,866 & 55.34 & 115,875 & 63.91 & \\
\hline \multicolumn{8}{|l|}{ Year of first diagnosis of asthma } \\
\hline 2004 & 23,728 & 12.72 & 1,116 & 21.55 & 22,612 & 12.47 & \multirow[t]{10}{*}{$<0.0001$} \\
\hline 2005 & 23,724 & 12.72 & 920 & 17.76 & 22,804 & 12.58 & \\
\hline 2006 & 21,994 & 11.79 & 709 & 13.69 & 21,285 & 11.74 & \\
\hline 2007 & 19,922 & 10.68 & 656 & 12.67 & 19,266 & 10.63 & \\
\hline 2008 & 19,109 & 10.25 & 597 & 11.53 & 18,512 & 10.21 & \\
\hline 2009 & 18,064 & 9.69 & 455 & 8.79 & 17,609 & 9.71 & \\
\hline 2010 & 16,369 & 8.78 & 267 & 5.16 & 16,102 & 8.88 & \\
\hline 2011 & 16,521 & 8.86 & 268 & 5.17 & 16,253 & 8.96 & \\
\hline 2012 & 14,947 & 8.01 & 149 & 2.88 & 14,798 & 8.16 & \\
\hline 2013 & 12,113 & 6.50 & 42 & 0.81 & 12,071 & 6.66 & \\
\hline \multicolumn{8}{|l|}{ Disability } \\
\hline None & 179,110 & 96.04 & 4,304 & 83.10 & 174,806 & 96.41 & \multirow[t]{2}{*}{$<0.0001$} \\
\hline Mild & 5,874 & 3.15 & 581 & 11.22 & 5,293 & 2.92 & \\
\hline
\end{tabular}


Table 1 General characteristics of the study population (Continued)

\begin{tabular}{|c|c|c|c|c|c|c|c|}
\hline Severe & 1,507 & 0.81 & 294 & 5.68 & 1,213 & 0.67 & \\
\hline \multicolumn{8}{|l|}{ Charlson comorbidity index } \\
\hline$\leq 1$ & 126,882 & 68.04 & 328 & 6.33 & 126,554 & 69.80 & \multirow[t]{4}{*}{$<0.0001$} \\
\hline 2 & 24,752 & 13.27 & 405 & 7.82 & 24,347 & 13.43 & \\
\hline 3 & 16,685 & 8.95 & 890 & 17.18 & 15,795 & 8.71 & \\
\hline$\geq 4$ & 18,172 & 9.74 & 3,556 & 68.66 & 14,616 & 8.06 & \\
\hline $\begin{array}{l}\text { Average pharmaceutical expenditures for asthma } \\
\text { in each year (KRW) }\end{array}$ & $24,773.30$ & $\pm 63,689.71$ & $51,765.29$ & $\pm 111,475.00$ & $24,002.30$ & $\pm 61,611.30$ & $<0.0001$ \\
\hline \multicolumn{8}{|l|}{ Region } \\
\hline Metropolitan & 83,723 & 44.89 & 2,001 & 38.64 & 81,722 & 45.07 & \multirow[t]{2}{*}{$<0.0001$} \\
\hline Other & 102,768 & 55.11 & 3,178 & 61.36 & 99,590 & 54.93 & \\
\hline Number of medical centers per 1000 residents & 9.17 & \pm 4.39 & 9.89 & \pm 5.11 & 9.15 & \pm 4.37 & $<0.0001$ \\
\hline Population size & $420,845.64$ & $\pm 259,860.18$ & $351,277.38$ & $\pm 259,532.33$ & $422,832.79$ & $\pm 259,596.53$ & $<0.0001$ \\
\hline Proportion of seniors (\%) & 12.09 & \pm 4.94 & 14.16 & \pm 6.42 & 12.03 & \pm 4.87 & $<0.0001$ \\
\hline Financial independence rate of local government (\%) & 59.06 & \pm 21.79 & 53.6 & \pm 22.60 & 59.22 & \pm 21.74 & $<0.0001$ \\
\hline Average follow-up (months) & 62.17 & \pm 34.26 & 38.43 & \pm 28.57 & 62.85 & \pm 34.17 & $<0.0001$ \\
\hline
\end{tabular}

SD standard deviation; NHI National Health Insurance; KRW Korean Won

\section{Discussion}

In the past several decades, South Korea has experienced rapid social and economic growth. The health status of South Koreans has also improved, and their lifespan has increased accordingly. Although burdens of illness due to acute diseases have decreased, chronic conditions now present new challenges [20]. Many researchers and healthcare professionals have made efforts to control such health problems including cancer, cardiovascular diseases, and cerebrovascular diseases, although certain issues remain. Specifically, relatively mild chronic diseases are not well managed, including asthma. In this

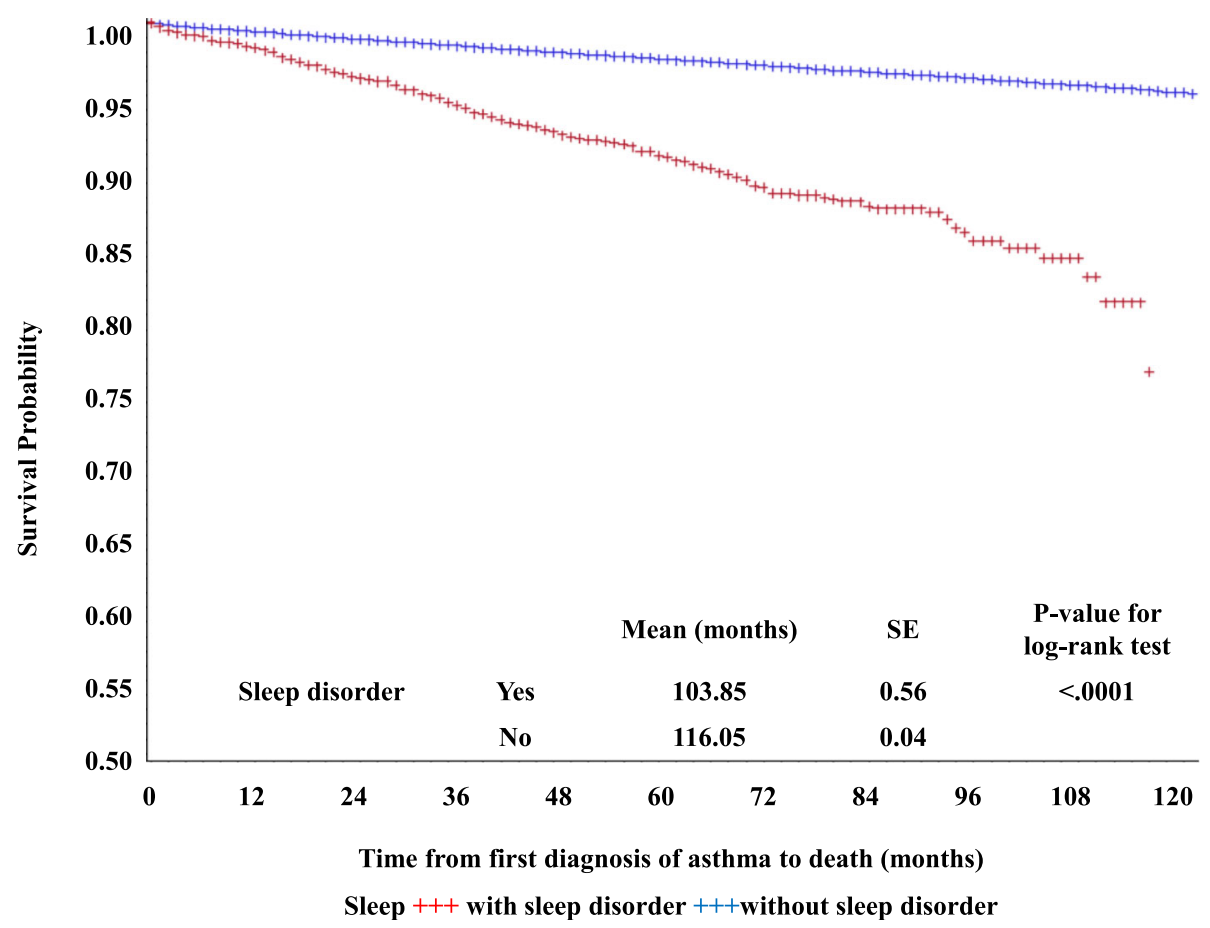

Fig. 1 Kaplan-Meier survival curves and log-rank test results comparing survival rates between patients with asthma, with (+++, dotted line) or without a sleep disorder (solid line) 
Table 2 Cox proportional hazard model for association between sleep disorders and mortality

\begin{tabular}{|c|c|c|c|c|}
\hline & \multirow[t]{2}{*}{$\mathrm{HR}$} & \multicolumn{2}{|l|}{$95 \% \mathrm{Cl}$} & \multirow[t]{2}{*}{$P$-value } \\
\hline & & Lower & Upper & \\
\hline \multicolumn{5}{|l|}{ Sleep disorder } \\
\hline Yes & 1.451 & 1.253 & 1.681 & $<0.0001$ \\
\hline No & 1.000 & - & - & - \\
\hline \multicolumn{5}{|l|}{ Sex } \\
\hline Male & 2.002 & 1.893 & 2.117 & $<0.0001$ \\
\hline Female & 1.000 & - & - & - \\
\hline \multicolumn{5}{|l|}{ Age (years) } \\
\hline$\leq 19$ & 1.000 & - & - & - \\
\hline $20-29$ & 2.865 & 1.809 & 4.540 & $<0.0001$ \\
\hline $30-39$ & 5.823 & 4.192 & 8.088 & $<0.0001$ \\
\hline $40-49$ & 14.144 & 10.603 & 18.866 & $<0.0001$ \\
\hline $50-59$ & 24.786 & 17.431 & 35.243 & $<0.0001$ \\
\hline $60-69$ & 57.397 & 39.115 & 84.224 & $<0.0001$ \\
\hline$\geq 70$ & 207.336 & 138.828 & 309.651 & $<0.0001$ \\
\hline \multicolumn{5}{|l|}{ Income (percentile) } \\
\hline$\leq 10$ (low) & 1.375 & 1.228 & 1.540 & $<0.0001$ \\
\hline $11-20$ & 1.390 & 1.219 & 1.585 & $<0.0001$ \\
\hline $21-30$ & 1.439 & 1.267 & 1.634 & $<0.0001$ \\
\hline $31-40$ & 1.476 & 1.306 & 1.668 & $<0.0001$ \\
\hline $41-50$ & 1.289 & 1.136 & 1.461 & $<0.0001$ \\
\hline $51-60$ & 1.337 & 1.185 & 1.507 & $<0.0001$ \\
\hline $61-70$ & 1.240 & 1.101 & 1.396 & 0.0004 \\
\hline $71-80$ & 1.227 & 1.098 & 1.371 & 0.0003 \\
\hline $81-90$ & 1.102 & 0.994 & 1.221 & 0.0651 \\
\hline$\geq 91$ (high) & 1.000 & - & - & - \\
\hline \multicolumn{5}{|l|}{ Insurance coverage } \\
\hline Medical aid & 1.546 & 1.317 & 1.814 & $<0.0001$ \\
\hline $\mathrm{NHI}$, self-employed insured & 1.126 & 1.061 & 1.195 & $<0.0001$ \\
\hline $\mathrm{NHI}$, employee insured & 1.000 & - & - & - \\
\hline \multicolumn{5}{|l|}{ Year of asthma diagnosis } \\
\hline 2004 & 1.000 & - & - & - \\
\hline 2005 & 0.884 & 0.808 & 0.967 & 0.0069 \\
\hline 2006 & 0.765 & 0.694 & 0.844 & $<0.0001$ \\
\hline 2007 & 0.859 & 0.776 & 0.951 & 0.0035 \\
\hline 2008 & 0.770 & 0.692 & 0.858 & $<0.0001$ \\
\hline 2009 & 0.784 & 0.697 & 0.882 & $<0.0001$ \\
\hline 2010 & 0.637 & 0.552 & 0.734 & $<0.0001$ \\
\hline 2011 & 0.603 & 0.518 & 0.702 & $<0.0001$ \\
\hline 2012 & 0.603 & 0.501 & 0.727 & $<0.0001$ \\
\hline 2013 & 0.671 & 0.487 & 0.925 & 0.0148 \\
\hline \multicolumn{5}{|l|}{ Disability } \\
\hline None & 1.000 & - & - & - \\
\hline Mild & 1.214 & 1.113 & 1.326 & $<0.0001$ \\
\hline
\end{tabular}


Table 2 Cox proportional hazard model for association between sleep disorders and mortality (Continued)

\begin{tabular}{|c|c|c|c|c|}
\hline Severe & 2.909 & 2.580 & 3.280 & $<0.0001$ \\
\hline \multicolumn{5}{|l|}{ Charlson comorbidity index } \\
\hline$\leq 1$ & 1.000 & - & - & - \\
\hline 2 & 1.437 & 1.122 & 1.840 & 0.0041 \\
\hline 3 & 1.568 & 1.169 & 2.105 & 0.0027 \\
\hline$\geq 4$ & 2.019 & 1.467 & 2.779 & $<0.0001$ \\
\hline Average annual pharmaceutical expenditures for asthma (per 10,000 KRW increase) & 1.003 & 1.000 & 1.005 & 0.018 \\
\hline \multicolumn{5}{|l|}{ Region } \\
\hline Metropolitan & 0.965 & 0.897 & 1.039 & 0.3419 \\
\hline Other & 1.000 & - & - & - \\
\hline Number of medical centers per 1000 residents (per 5 increase) & 1.016 & 0.987 & 1.047 & 0.2789 \\
\hline Population size (per 100,000 increase in population) & 0.977 & 0.962 & 0.992 & 0.0029 \\
\hline Proportion of seniors (per 10\% increase) & 0.940 & 0.883 & 1.000 & 0.0502 \\
\hline Financial independence rate of local government (per 10\% increase) & 0.978 & 0.961 & 0.996 & 0.0166 \\
\hline
\end{tabular}

$\mathrm{Cl}$ confidence interval; HR hazard ratio; $\mathrm{NHI}$ National Health Insurance; KRW Korean Won

Table 3 Subgroup analysis using Cox proportional hazard model by age, insurance coverage, average pharmaceutical expenditures, region, and number of medical centers

\begin{tabular}{|c|c|c|c|c|}
\hline & \multirow[t]{2}{*}{$H R$} & \multicolumn{2}{|l|}{$95 \% \mathrm{Cl}$} & \multirow[t]{2}{*}{$P$-value } \\
\hline & & Lower & Upper & \\
\hline \multicolumn{5}{|l|}{ Age (years) } \\
\hline$\leq 29$ & 7.351 & 1.735 & 31.139 & 0.0068 \\
\hline $30-59$ & 1.415 & 0.865 & 2.313 & 0.1665 \\
\hline$\geq 60$ & 1.301 & 1.097 & 1.543 & 0.0025 \\
\hline \multicolumn{5}{|l|}{ Insurance coverage } \\
\hline Medical aid & 0.690 & 0.316 & 1.508 & 0.3518 \\
\hline $\mathrm{NHI}$, self-employed insured & 1.647 & 1.305 & 2.078 & $<0.0001$ \\
\hline $\mathrm{NHI}$, employee insured & 1.327 & 1.083 & 1.626 & 0.0063 \\
\hline \multicolumn{5}{|c|}{ Average annual pharmaceutical expenditures for asthma } \\
\hline Below median & 1.447 & 1.116 & 1.876 & 0.0052 \\
\hline Above median & 1.466 & 1.229 & 1.751 & $<0.0001$ \\
\hline \multicolumn{5}{|l|}{ Region } \\
\hline Metropolitan & 1.370 & 1.087 & 1.727 & 0.0078 \\
\hline Other & 1.508 & 1.248 & 1.825 & $<0.0001$ \\
\hline \multicolumn{5}{|c|}{ Number of medical centers per 1000 residents } \\
\hline Below median & 1.609 & 1.302 & 1.988 & $<0.0001$ \\
\hline Above median & 1.323 & 1.079 & 1.622 & 0.0071 \\
\hline \multicolumn{5}{|l|}{ Charlson comorbidity index } \\
\hline$\leq 2$ & 1.359 & 1.148 & 1.610 & 0.0004 \\
\hline$\geq 3$ & 1.553 & 1.020 & 2.364 & 0.0401 \\
\hline
\end{tabular}

$\mathrm{Cl}$ confidence interval; HR hazard ratio; $\mathrm{NHI}$ National Health Insurance. The results of the subgroup analysis to investigate differences in the association between sleep disorders and mortality according to age, insurance coverage, average annual pharmaceutical expenditures for asthma, region, number of medical centers, and Charlson comorbidity index. The $P$-value in type 3 tests for models with interactions between sleep disorders and subgroup variables were as follows: model with interaction between age and sleep disorders, $P$-value in type 3 test $=0.2249$; model with interaction between insurance coverage and sleep disorders, $P$-value in type 3 test $=0.1742$; model with interaction between average annual pharmaceutical expenditures for asthma and sleep disorders, $P$-value in type 3 test $=$ 0.4199; model with interaction between region and sleep disorders, $P$-value in type 3 test $=0.3216$; model with interaction between number of medical centers and sleep disorders, $P$-value in type 3 test $=0.6448$; model with interaction between Charlson comorbidity index and sleep disorders, $P$-value in type 3 test $=0.0427$ 
area, South Korea lags behind other OECD countries [11]. According to health professionals, the difficulties of asthma management in South Korea are related to shortcomings in primary care, and they have suggested that continuity of care for asthma patients through primary care could improve health outcomes in this population. However, innovative changes in South Korean primary care are difficult to implement [21]. We focused on the relationship between sleep disorders and mortality in asthma patients to determine if addressing this issue could help this patient population.

Our findings suggest that the presence of sleep disorders in patients previously diagnosed with asthma is associated with an increased mortality risk. Previous studies have reported that sleep disorders affect overall quality of life and can deteriorate patients physically and psychologically [22-25]. Given the worsening status of asthma management and increasing numbers of patients diagnosed with sleep disorders, we specifically focused on the relationship between sleep disorders and mortality in patients with asthma. In South Korea, patients have been able to receive healthcare with 20\%-30\% copayment since the introduction of NHI in 1989 [26]. However, patients who visit medical institutions due to sleep disorders only receive health insurance coverage for sleep apnea based on the criterion of the respiratory distress index. This suggests that certain patients may not have received appropriate treatment. Therefore, it may be appropriate to revise the insurance coverage criteria to reduce avoidable death in patients with asthma. Additionally, improving the accessibility of healthcare by reducing copayments via insurance policy changes may prevent the worsening status of asthma patients with sleep disorders, even if there is no direct impact on mortality. Furthermore, we expect that such an impact may be helpful in patients with asthma as well as in patients with other chronic diseases, from a health policy perspective.

Subgroup analyses revealed several interesting results. The increased mortality in patients with asthma and sleep disorders was greater for younger patients, those with NHI self-employed insurance, those in non-metropolitan areas, and those in regions with low healthcare accessibility. First, younger patients had more negative outcomes, which had been previously reported [27]. This suggests that careful management for younger asthma patients could prevent their condition from worsening. Second, patients with sleep disorders who had NHI self-employed insurance had a higher mortality rate. This indicates that the evaluation criteria for beneficiaries of health insurance could benefit from revision. In South Korea, the government medical aid program is for patients with an income below the government-defined poverty level. However, the evaluation for patients who receive NHI self-employed insurance could have overestimated their socioeconomic level compared to those with NHI employee insurance due to evaluation methods. It is therefore possible that they could have more limited access to healthcare and might not receive appropriate treatment. Based on these results, health policymakers must reconsider the evaluation methods for health insurance beneficiaries [28]. Also, differences in regional characteristics could affect patient outcomes. This is another issue that could be addressed with government interventions. Finally, the significant interaction between sleep disorders and the CCI was observed in this study. As already mentioned, CCI was usually used to consider comorbidities that could affect health outcomes of patients. Thus, the presence of interaction means that the occurrence of sleep disorder in asthma patient with more comorbidities could affect to more worsening their status, and could not well manage their condition than patient with less comorbidities [29]. Therefore, healthcare professionals were needed to carefully provide care for patient considering their comorbidity condition.

Our study had several strengths compared to previous publications. First, we used national sampling cohort data to assess the relationship between sleep disorders and mortality risk in patients with asthma. Such data are particularly helpful for establishing evidence-based policies to effectively manage asthma patients. Next, to the best of our knowledge, this study is the first study to investigate the impact of sleep disorders on the mortality risk of asthma patients in South Korea. Other previous reports described the negative effects of sleep disorders and relationships between sleep disorders and health outcomes. However, few studies have regarded the relationship between sleep disorders and mortality in patients with asthma in South Korea. Thus, our findings could provide useful evidence for the development of policies or programs to better manage patients with asthma and sleep disorders. Finally, we made a concerted effort to reduce the limitations of secondary data by adjusting covariates for patients' clinical and regional characteristics. We included the year of asthma diagnosis, disability, Charlson comorbidity index score, and average annual pharmaceutical expenditures due to asthma to reflect disease severity and included regional characteristics to consider differences in medical accessibility by area.

Our study also had several limitations. Although several factors that affect mortality were included in this study, more detailed information such as socioeconomic factors was not available [30]. Given that the average period from the first diagnosis for asthma to death was about 9 years, there were several potential confounders related to managing asthma, such as detailed severity indicators and smoking status, which could have influenced the health outcomes of patients with asthma. Unfortunately, we could not assess such confounders in this study due to 
data limitations, as the data used in this study were claim data that were collected to provide payment for both patients and providers based on medical utilization. Second, we did not have detailed information regarding patient income level, as the data were collected based on NHI criteria for the overall economic status of a population; detailed income described in monetary units was not included. Third, in investigating the association between the occurrences of sleep disorders and morality as an outcome variable, we only focused on patients with asthma rather than the general population. Therefore, there were several concerns regarding the external validity of the whole population in this study. Finally, the occurrences of sleep disorders may have decreased as the status of patients with asthma worsened; thus, they may not have been a direct risk factor for death. However, we only used all-cause mortality as an outcome variable in this study rather than measuring symptom indicators such as pulmonary function test results. Therefore, we were unable to consider the other changes by occurrences of sleep disorders among patients with asthma in this study, and this may have caused over- or underestimation of the impact of sleep disorders. In addition, although the data included detailed causes of death, the sample size was too small to analyze the covariates used in this study (e.g., respiratory-specific mortality: $0.34 \%$ ).

Despite these limitations, our findings suggest that sleep disorders in patients previously diagnosed with asthma are negatively associated with their health status, and in particular, mortality. Although further studies using more detailed data will be needed, these results underscore the need for health policymakers and healthcare professionals to identify effective ways to reduce the prevalence of sleep disorders in South Korea.

\section{Conclusion}

Sleep disorders in asthma patients are associated with higher mortality. Considering the worsening status of asthma management and the rapid growth of sleep disorders in South Korea, health policymakers should consider developing effective interventions based on our findings.

\section{Abbreviations}

NHIS: National Health Insurance Service; HR: Hazard ratio; Cl: Confidence interval; WHO: World Health Organization; OECD: Organization for Economic Co-operation and Development; ICD: International Classification of Diseases; NHI: National Health Insurance; SE: Standard error

\section{Acknowledgements}

\section{Funding}

No specific funding supported this study.

\section{Availability of data and materials}

The data used in this study were obtained from the NHIS National Sample Cohort and can only be disclosed to those who have authorization from NHIS.

\section{Authors' contributions}

KTH designed the study, collected the data, performed the statistical analyses, and wrote the manuscript. BHC, SGL, SJK, WK, HJL, YJJ, and ECP contributed to the Discussion section and reviewed and edited the manuscript. ECP is the guarantor of this work and, as such, had full access to all of the data in the study and takes responsibility for the integrity of the data and the accuracy of the data analysis. The text in this document has been checked by at least two professional editors who are native English speakers. All authors read and approved the final manuscript.

\section{Competing interests}

The authors declare that they have no competing interests.

Consent for publication

Not applicable.

\section{Ethics approval and consent to participate}

The data used in our study comprised details of patients' utilization of healthcare. This study was approved by the Institutional Review Board, Yonsei University Graduate School of Public Health (2014-239). This study did require informed consent from the patients, as patient information was anonymized and unidentified prior to analysis.

\section{Author details}

'Department of Public Health, Graduate School, Yonsei University, Seoul, Republic of Korea. ${ }^{2}$ Institute of Health Services Research, Yonsei University College of Medicine, Seoul, Republic of Korea. ${ }^{3}$ Office of Communication, Korea Centers for Disease Control and Prevention, Cheongju, Republic of Korea. ${ }^{4}$ Department of Hospital Management, Graduate School of Public Health, Yonsei University, Seoul, Republic of Korea. ${ }^{5}$ Department of Preventive Medicine, Yonsei University College of Medicine, Seoul, Republic of Korea.

Received: 23 March 2016 Accepted: 7 November 2016

Published online: 17 November 2016

\section{References}

1. Beasley $\mathrm{R}$, of Asthma TIS. Worldwide variation in prevalence of symptoms of asthma, allergic rhinoconjunctivitis, and atopic eczema: ISAAC. Lancet. 1998; 351(9111):1225-32.

2. Asthma. [http://www.who.int/respiratory/asthma/en/]. Accessed 14 Jan 2016.

3. Akinbami LJ, Schoendorf KC. Trends in childhood asthma: prevalence, health care utilization, and mortality. Pediatrics. 2002;110(2):315-22.

4. Grant EN, Lyttle CS, Weiss KB. The relation of socioeconomic factors and racial/ethnic differences in US asthma mortality. Am J Public Health. 2000; 90(12):1923

5. McCoy L, Redelings M, Sorvillo F, Simon P. A multiple cause-of-death analysis of asthma mortality in the United States, 1990-2001. J Asthma. 2005:42(9):757-63.

6. Jørgensen IM, Jensen VB, Bülow S, Dahm TL, Prahl P, Juel K. Asthma mortality in the Danish child population: risk factors and causes of asthma death. Pediatr Pulmonol. 2003;36(2):142-7.

7. Roberts G, Patel N, Levi-Schaffer F, Habibi P, Lack G. Food allergy as a risk factor for life-threatening asthma in childhood: a case-controlled study. J Allergy Clin Immunol. 2003;112(1):168-74.

8. Ten Brinke A, Sterk P, Masclee A, Spinhoven P, Schmidt J, Zwinderman A, Rabe K, Bel E. Risk factors of frequent exacerbations in difficult-to-treat asthma. Eur Respir J. 2005:26(5):812-8.

9. Yigla M, Tov N, Solomonov A, Rubin AHE, Harlev D. Difficult-to-control asthma and obstructive sleep apnea. J Asthma. 2003;40(8):865-71.

10. Schwartz J, Slater D, Larson TV, Pierson WE, Koenig JQ. Particulate air pollution and hospital emergency room visits for asthma in Seattle. Am Rev Respir Dis. 1993;147(4):826-31.

11. OECD Health Statistics. [http://dx.doi.org/10.1787/health-data-en]. Accessed 14 Jan 2016.

12. Grandner MA, Patel NP. From sleep duration to mortality: implications of meta-analysis and future directions. J Sleep Res. 2009:18(2):145-7.

13. Jean RE, Gibson CD, Jean RA, Ochieng P. Obstructive sleep apnea and acute respiratory failure: An analysis of mortality risk in patients with pneumonia requiring invasive mechanical ventilation. J Crit Care. 2015;30:778-83. 
14. Baldwin CM, Griffith KA, Nieto F, O'Connor GT, Walsleben JA, Redline S. The association of sleep-disordered breathing and sleep symptoms with quality of life in the Sleep Heart Health Study. Sleep. 2001;24(1):96-105.

15. National Health Insurance Service: Statistics for diseases: sleeping disorder. 2015.

16. E-provincial indicators. [http://kosis.kr/statHtml/statHtml.do?orgld=101\&tblld= DT_1YL2501\&conn_path=12]. Accessed 14 Jan 2016.

17. Choi JW, Park E-C, Chun S-Y, Han K-T, Han E, Kim TH. Health care utilization and costs among medical-aid enrollees, the poor not enrolled in medical-aid, and the near poor in South Korea. Int J Equity Health. 2015;14(1):128.

18. Kim J-H, Lee K-S, Yoo K-B, Park E-C. The differences in health care utilization between Medical Aid and health insurance: a longitudinal study using propensity score matching. PloS one. 2015;10(3):e0119939.

19. Platt RW, Joseph K, Ananth CV, Grondines J, Abrahamowicz M, Kramer MS. A proportional hazards model with time-dependent covariates and timevarying effects for analysis of fetal and infant death. Am J Epidemiol. 2004; 160(3):199-206.

20. Kwon S. Thirty years of national health insurance in South Korea: lessons for achieving universal health care coverage. Health Policy Plan. 2009;24(1):63-71.

21. Cho S-H, Park H-W, Rosenberg DM. The current status of asthma in Korea. J Korean Med Sci. 2006;21(2):181-7.

22. Manocchia M, Keller S, Ware JE. Sleep problems, health-related quality of life, work functioning and health care utilization among the chronically ill. Qual Life Res. 2001;10(4):331-45.

23. Zeitthofer J, Schmeiser-Rieder A, Tribl G, Rosenberger A, Bolitschek J, Kapfhammer G, Saletu B, Katschnig H, Holzinger B, Popovic R. Sleep and quality of life in the Austrian population. Acta Neurol Scand. 2000;102(4):249-57.

24. Dew MA, Hoch CC, Buysse DJ, Monk TH, Begley AE, Houck PR, Hall M, Kupfer DJ, Reynolds III CF. Healthy older adults' sleep predicts all-cause mortality at 4 to 19 years of follow-up. Psychosom Med. 2003;65(1):63-73.

25. Punjabi NM, Caffo BS, Goodwin JL, Gottlieb DJ, Newman AB, O'Connor GT, Rapoport DM, Redline S, Resnick HE, Robbins JA. Sleep-disordered breathing and mortality: a prospective cohort study. PLoS Med. 2009;6(8):873.

26. Jeong H-S. Korea's National Health Insurance-lessons from the past three decades. Health Aff. 2011;30(1):136-44.

27. Campbell M, Cogman G, Holgate S, Johnston S. Age specific trends in asthma mortality in England and Wales, 1983-95: results of an observational study. BMJ. 1997;314(7092):1439.

28. Yu S-H, Anderson GF. Achieving universal health insurance in Korea: a model for other developing countries? Health Policy (New York). 1992;20(3):289-99.

29. Charlson ME, Charlson RE, Peterson JC, Marinopoulos SS, Briggs WM, Hollenberg JP. The Charlson comorbidity index is adapted to predict costs of chronic disease in primary care patients. J Clin Epidemiol. 2008;61(12):1234-40.

30. Marder D, Targonski P, Orris P, Persky V, Addington W. Effect of racial and socioeconomic factors on asthma mortality in Chicago. CHEST J. 1992; 101(6 Supplement):426S-9S.

\section{Submit your next manuscript to BioMed Central and we will help you at every step:}

- We accept pre-submission inquiries

- Our selector tool helps you to find the most relevant journal

- We provide round the clock customer support

- Convenient online submission

- Thorough peer review

- Inclusion in PubMed and all major indexing services

- Maximum visibility for your research

Submit your manuscript at www.biomedcentral.com/submit

) Biomed Central 